\title{
Implementation of One and a Half Breaker Arrangement in Fierza 220 KV Substation with Prozanet Scada System
}

\author{
Eni Saqe * \\ Prof.Asoc.Dr. Marialis Celo* \\ Phd. Marjela Qemali* \\ ${ }^{*}$ Polytechnic Univeristy of Tirana, Faculty of Electric Engineering \\ Email: eni_saqe@yahoo.com
}

\section{Doi:10.5901/ajis.2015.v4n2s2p167}

\section{Abstract}

Fierza Substation has a one and a half circuit breaker arrangement. In Fierza Substation scheme, two busbars are connected through three circuit breakers. The name one and a half breaker coin the fact that each circuit has the "own" breaker and the middle breaker has to be used from both circuits. In normal operation when all elements are in working condition, all circuit breakers (C1, C2 and C3) are closed and both busbars are energized and share the load through each other. Any circuit failure will trip just the two circuit breakers adjacent to the fault, in order to isolate it. No other circuit breaker will have be affected from this fault. If a busbar short circuit happens only the breakers near to the busbar will trip and all the other circuits will proceed supplying power. In this arrangement it is also possible to take out of service both busbars, and still supply the transmission line directly through the middle circuit breaker (C2) from the generator directly. The last case is only possible if both circuit's generator and supplied transmission line are in the same diameter. The philosophy of operation of such a scheme as a case study of Fierza Substation and the problems of operating this scheme from two different Authorities (KESH and OST) at the same time, is discussed in this paper. The implementation of this case is shown with Prozanet Scada system.

Keywords: One and a half circuit breaker, Prozanet, Scada, Control Authority

\section{Substation Description}

The unbundling process of Public Utility Albanian Power Corporation -KESH started in 2004 and was focused on:

- Functional unbundling (the three core activities: generation, transmission and distribution \& retail supply);

- Accounting unbundling (identification of costs for each service/function);

- Legal unbundling (corporatization) - The Transmission System Operator was registered firstly as joint stock company on 2004 and in 2005 the Transmission System Operator was legally unbundled; in 2008 the Distribution System Operator (performing the retail service as well) was legally unbundled;

- The privatization of the DSO started in 2008 and was finalized in mid of 2009. Actually, after an unsuccessful privatization process, the distribution company moved back at the end of 2014 to a $100 \%$ state owned company.

Due to the decentralisation process of OST and KESH, 14 Substations 220 and $400 \mathrm{kV}$, were taken into ownership and administration of OST sh.a. Since the rehabilitation of HPP Vau Dejes and HPP Fierza was finalized by that time, a common control system for the Hydro power plants and the relevant Substation was implemented from Alstom with Alspa P320 El Control Center.

The unbundling process of OST and KESH was accompanied with problems of operation and maintenance of the Drin river cascade substations. The problems were related with the fact that the previous Control Center (Alspa P320) with all the appropriate infrastructure for the operation of hydro power as well as Substation is located in the premises of the respective Hydro power plant. The physical separation of Hydro power plant and Substation is simple because the building of the plant and the respective Control Center are located below the substation about 180 meter above sea level and the Substation itself is placed above the Hydro Power plant 300 meter above Sea level. The relay building near the substation doesn't have any monitoring infrastructure for switching elements, while the hydropower plant staff had full monitoring and Control for the substation. In case of defects or malfunctioning of the switching elements at the substation, staffs from both companies organized jointly inspected mission to solve the problem. The switching devices were very old 
and without a proper maintenance, so it was a high priority the replacements with new elements that promise a reliable operation.

Arrangement schemes in substations are very important for the safe and reliable power connection of the transmission circuits, where the requested power flow is transmitted and the voltage level is held within the accepted range. These schemes ensures the guaranty of power supply to the consumers in case that a failure occurs or even if maintenance works are in progress.

The designer of a substation develops his project based on some basic principles:

- requested reliability of supply

- requested flexibility of the arrangement

- Low erecting cost

- simple and safe maintenance and operation

Fierza Substation has a one and a half circuit breaker arrangement. In Fierza Substation scheme, two busbars are connected through three circuit breakers. The name one and a half breaker coin the fact that each circuit has the "own" breaker and the middle breaker has to be used from both circuits. In normal operation when all elements are in working condition, all circuit breakers (C1, C2 and C3) are closed and both busbars are energized and share the load through each other. Any circuit failure will trip just the two circuit breakers adjacent to the fault, in order to isolate it. No other circuit breaker will have be affected from this fault. If a busbar short circuit happens only the breakers near to the busbar will trip and all the other circuits will proceed supplying power. In this arrangement it is also possible to take out of service both busbars, and still supply the transmission line directly through the middle circuit breaker (C2) from the generator directly. The last case is only possible if both circuit's generator and supplied transmission line are in the same diameter.

\section{The aim of the investment}

The priorities of the insfrastructure investments at OST Fierza substation were:

A. At first the new implemented system should be able to fully monitor and control the primary scheme of Fierza substation.

B. It should also be ensured that the new protections perform their protection function without affecting the existing protections of the hydropower units, which also trip the substation circuit breakers.

C. The works should be carried out ensuring continuous operation of the existing monitoring scheme of hydro power plant control centre.

D. Controls of existing KESH SCADA ALSPA Centre, should be removed only for C3 Circuit Breakers(see figure $11 \mathrm{C} 3,2 \mathrm{C} 3,3 \mathrm{C} 3$ and $4 \mathrm{C} 3$ are the Circuit Breakers next to busbar $2 \mathrm{BB} 2$ and are not relevant for the operation of the generators) and $110 \mathrm{kV}$ voltage levels.

E. Regarding breaker $\mathrm{C} 2$ (see figure 1 1C2, 2C2, 3C2 and 4C2 are the middle Circuit Breakers betwen busbar 2 BB2 and Busbar 1 BB1 and are necessary to synchronize the generators on the second busbar BB2 or on the respective line) a solution needed to be found that gave both companies the opportunity to control this Breaker but the decision who will have the hierarchy should be taken from OST, since these circuit Breakers are OST property.

F. Regarding breaker $\mathrm{C} 1$ (see figure $1 \mathrm{C} 1,2 \mathrm{C} 1,3 \mathrm{C} 1$ and $4 \mathrm{C} 1$ are the Circuit Breakers next to busbar $1 \mathrm{BB} 1$ and are necessary to synchronize the generators on the first busbar BB1) a solution needed to be found that gave to both companies the opportunity to control this Breaker but the decision who will have the hierarchy should be taken from KESH, since these circuit breakers are KESH property.

\section{New Elements at Fierza 220 kV control system}

At Fierza substation scheme Figure 1 we have on the $220 \mathrm{kV}$ busbars a diameter for each generator as well as an Autotransformer related diameter. Autotransformer bay DA has also predicted a spare line that can be connected at 220 $\mathrm{kV}$ side.

From the scheme Figure 1 it appears that the Autotransformer can be supplied from each busbar. Line 9 Burrel, 10 Tirana, 11 Koman and 12 Prizren can be supplied on request only from the second busbars or only the first busbars as well as the from the respective generator.

Interesting from the standpoint of supply is that the cooperation strategies between Albania and the Power System of Kosovo have envisaged that a generating unit and specifically unit 4 can be attributed to Kosovo and thus to work as 
secondary regulation unit for the needs of the Kosovo power system, keeping circuit breakers 4C1 and 4C3 open.

In this way the line 12 Fierze- Prizren and unit 4 are dedicated to each other and do not affect further operations of $220 \mathrm{kV}$ busbars.

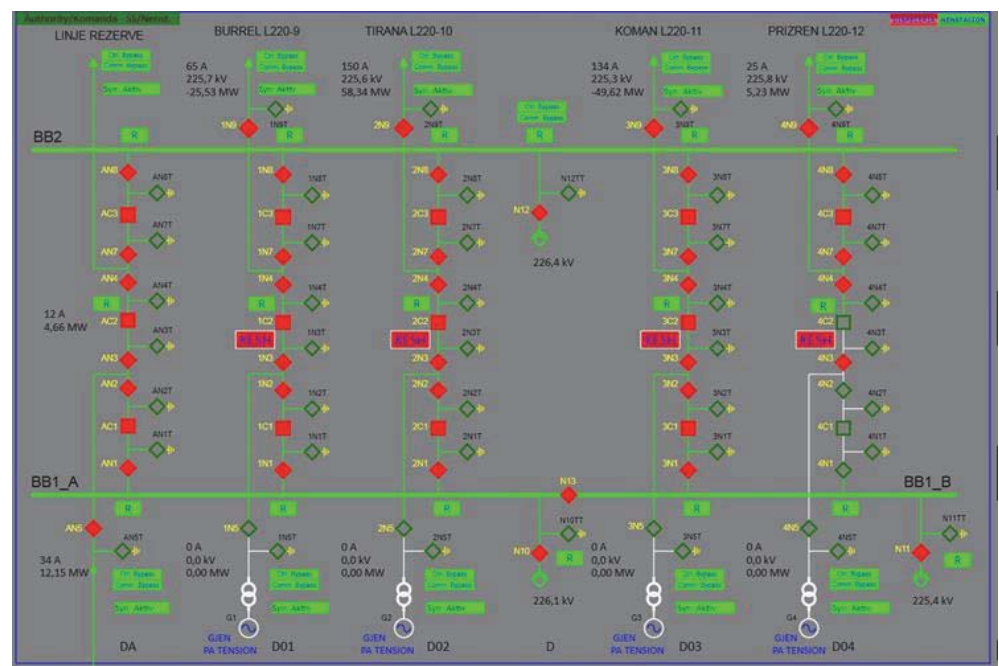

Figure 1: Prozanet 220 kV Fierza scheme display

Since the synchronization of Fierza's generators is achieved through the circuit breakers $\mathrm{C} 1$ or $\mathrm{C} 2$, the control of the respective circuit breakers or disconnectors should be carried not only from OST out but also from KESH. Regardless that the circuit breakers $1 \mathrm{C} 1,2 \mathrm{C} 1,3 \mathrm{C} 1$ and $4 \mathrm{C} 1$ including the respective disconnectors are owned by $\mathrm{KESH}$ and on the other hand the circuit breakers $1 \mathrm{C} 2,2 \mathrm{C} 2,3 \mathrm{C} 2$ and $4 \mathrm{C} 2$ including the respective disconnectors are owned by OST, the control of all these units may be possible to be carried out by KESH and OST too. In order to have a clearly distinct authority of control there have been placed the logical switches which can be controlled for every bay in particularity at the respective control panel. Hence the control of the $1 \mathrm{C} 2,2 \mathrm{C} 2,3 \mathrm{C} 2$ and $4 \mathrm{C} 2$ circuit breakers passes, in manual mode by the OST staff at the respective control panel, in KESH state or OST state. This functionality has become notable at the local SCADA through the Prozanet logical function "PM Block". This has been carried out through the co-operation with Koncar company, and will be explained hereinafter.

The control of the Circuit breakers $1 \mathrm{C} 1,2 \mathrm{C} 1,3 \mathrm{C} 1$ and $4 \mathrm{C} 1$ is under the OST jurisdiction, in case that the disconnector N5 of the respective generator is open, and vice versa if N5 is closed the control is under KESH jurisdiction.

The N5 disconnector is only closed when the respective unit needs to be synchronized with the system. The two logical switches, the one at the control panel of OST and the other one which is the unit disconnector N5, which in this case has taken the attributes of a logical switch, provides the appropriate plus of control singly to the company which has the priority of the control, thus excluding the eventual disagreements concerning the given commands.

Below is given an explanation about the elements that are used in order to implement the requested schematic and the functionality of each element.

\subsection{Servers at the control panel}

Servers are central units that gather all the information data that are generated from all the control relays and protection relays, and that passes through Ruggedcom switches.

The very first server, the upper units shown in figure 2, stands consistently in function while the second server stands in watchdog application state. If for any case or situation the first server fails, then the second server takes over, so that it is guaranteed the system has full operating functionality, even in case of an failure, the information data that are provided from the relays is maintained. 


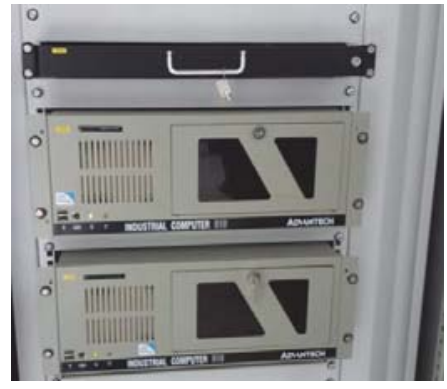

Figure 2: Servers at the control panel

\subsection{GPS (Global position system)}

Is the time server that provides the exact time for all the composite equipments of the protection system and control monitoring.

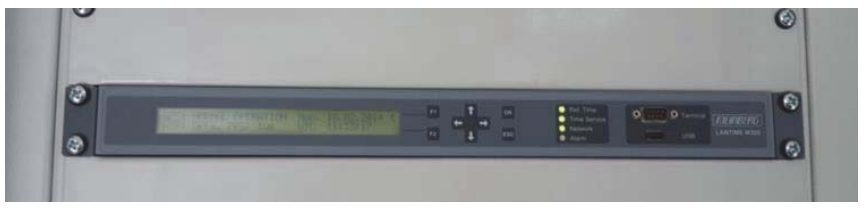

Figure 3: GPS (Global position system)

\section{3 cRuggedcom RSG2100}

These equipments, which in other words we can call them communication hub, include all the gathered data that comes from relays through the optical fibers and route it to the servers.

\subsection{Operator Workstations}

Through the workstations we are able to monitoring the situation of the substation, to receive data from the alerts that comes from the relays, to be informed for the positions of all primary equipments of the substations and also to be able to have the possibility of controlling them by giving control command through the workstation. Therefore these units are the ones that provide the interface between the operator and the control system.

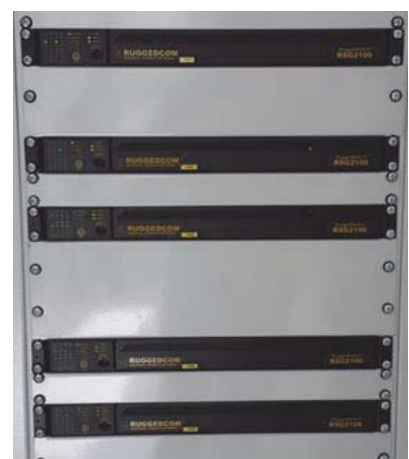

Figure 4: Ruggedcom RSG2100 
It is possible to monitor at any time the primary schematic positions of the substation, to take information regarding eventual events and we have the possibility that by just clicking to perform a requested operation.

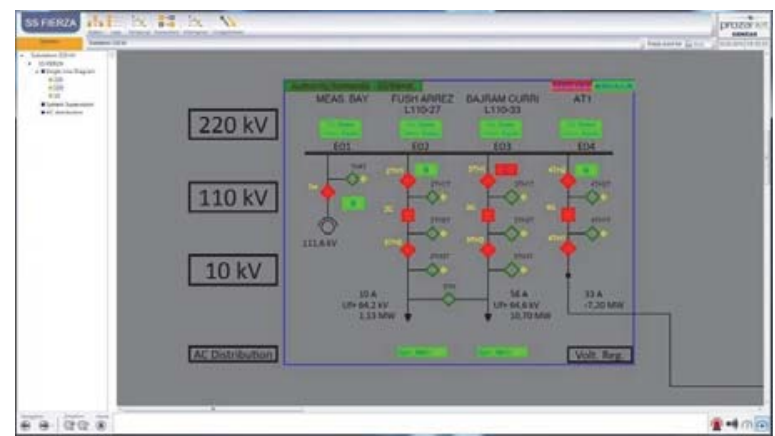

Figure 5: Prozanet Fierza 110 kV schematic

At the primary schematic figure 5 we are able to see the control authority between Dispatching Centre (with red color) and the local authority at the workstation (substation with green color). The switch of the authority is made by giving the respective command which can be seen at the monitor by clicking 'Dispatcher' or 'Substation'.

At the schematic every single color has an assigned meaning as follows:

1. Green color indicates the $220 \mathrm{kV}$ voltage level.

2. Black color indicates the $110 \mathrm{kV}$ voltage level.

3. White color indicates that there is no voltage.

4. Pink color indicates that there is no communication or no information from the relays.

5. Yellow color indicates that respective schematics are grounded.

Regarding the colors of the disconnectors /circuit breakers, there are the following descriptions:

1. Red fillet color indicates the circuit breaker / disconnector at the locked or closed state.

2. Green blank color indicates the circuit breaker / disconnector at the unlocked or disconnected state.

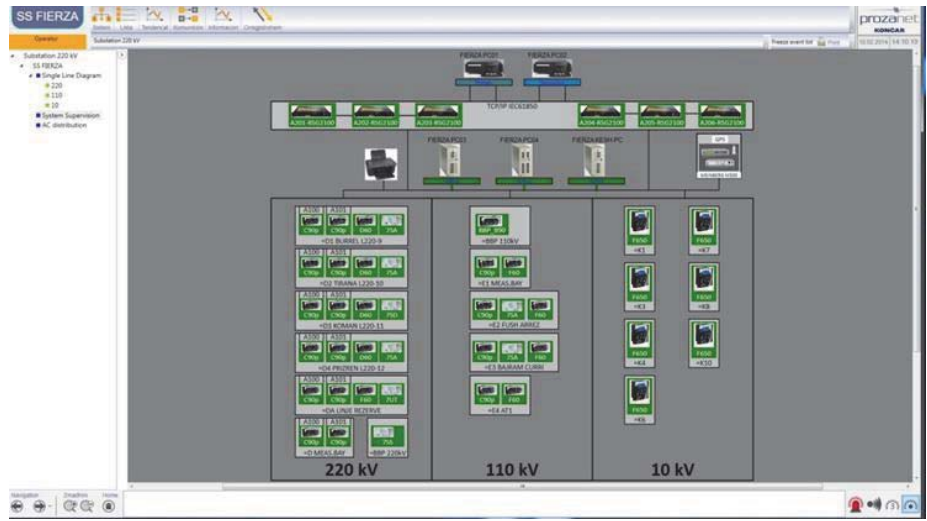

Figure 6: Self system supervision display

At the communication schematic that is shown at the monitor figure 6, we can look at the all relays that are linked with our system. Through colors it is possible to identify the communication state as follows:

1. Red - indicates communication problem or fault.

2. Green - indicates that communication with the respective relay is in order. 


\subsection{Event list}

Figure 7 shows all the events in the substation.

Through means of clicking at each tabulator we can obtain the appropriated information.

"Events" represent all the occurred events in the substation according to the time chronic. We have the opportunity that by clicking to the upper box of the respective event to gain the required information at that time, in example in order to gain information regarding the Burrel's line: we have to type down below the respective column (event name): Burrel ose L220-9 and after that the events list will show only the information gathered from the relays that holds the name Burrel or L220-9.

"Faults": At the "Faults": tabulator figure 8 we can see the active alerts that reaches our system at this very moment of time. In case that after an alarm shows up we press the Acknowledge button, afterwards at the fault list remains only the faults that are still active.

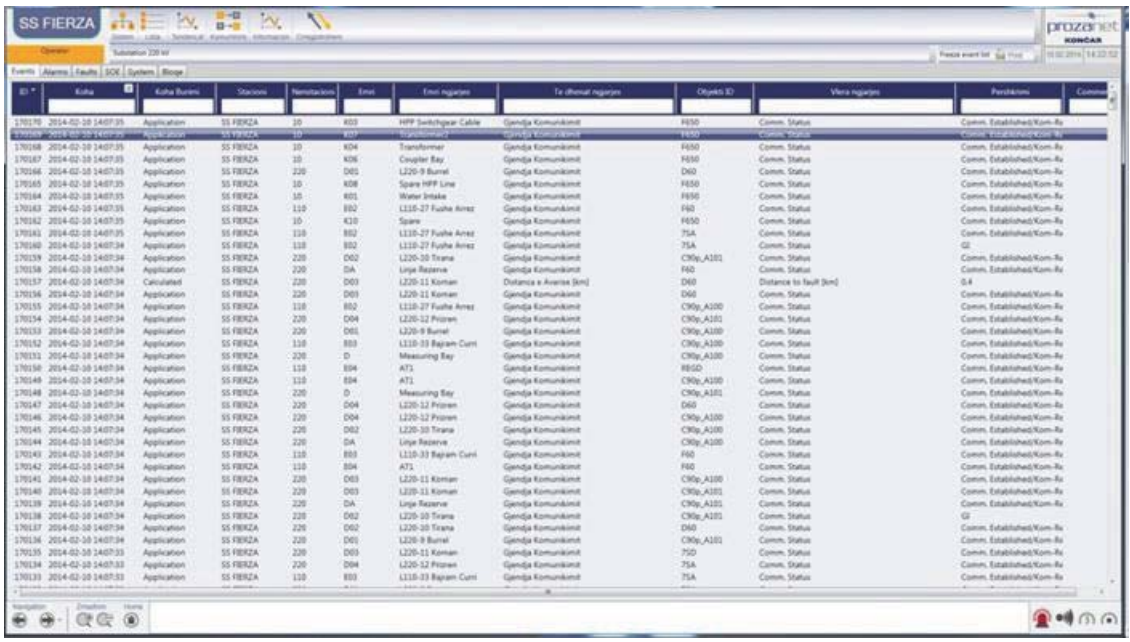

Figure 7: Event List

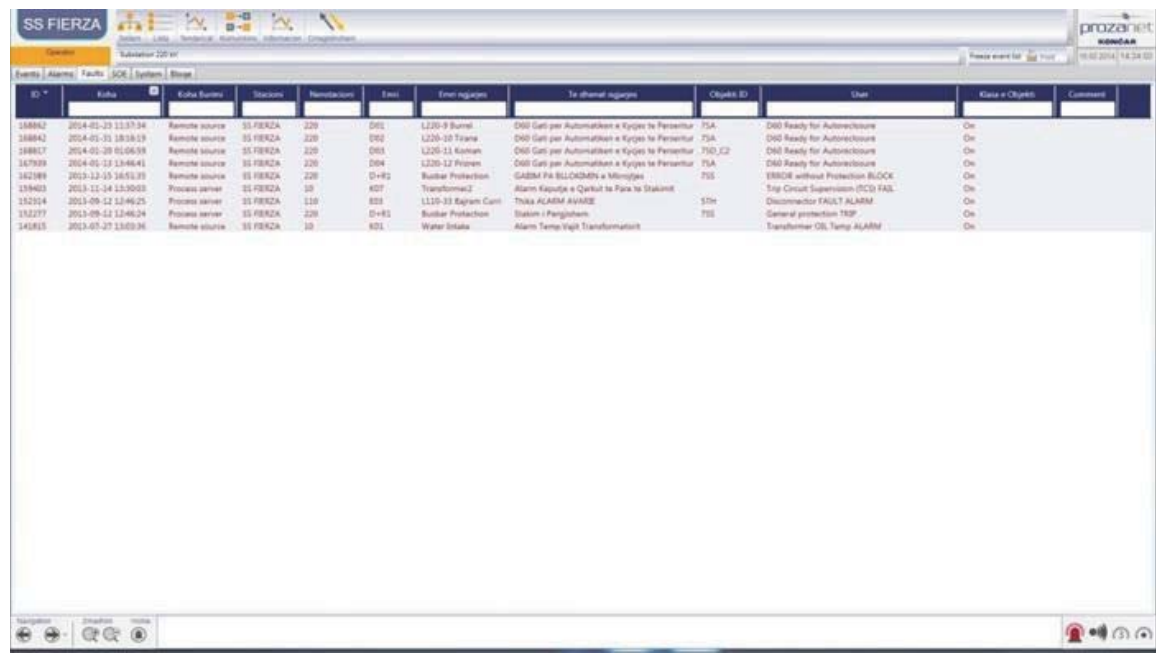

Figure 8: Alarm List 


\subsection{Control levels}

The control levels are accomplished in accordance with the principle form the highest to the lowest level.

1. The $5^{\text {th }}$ level of command is the control from National Dispatcher Centre Scada.

2. The $4^{\text {th }}$ level of command is the control from local Scada with the Prozanet operator interface.

3. The $3^{\text {rd }}$ level of command is the control form the control relay (C90p).

4. The $2^{\text {nd }}$ level of command is the control through mimic board (the panel below the control relay).

5. The $1^{\text {st }}$ level of command is control on the yard.

It must be taken into account that for the execution of the proper command the full logical conditions must be fulfilled. If the execution from the workstation does not function, accordingly we have to pass the command to the next lower level.

From the workstation it is possible to exclude the synchrocheck function.

Through the control relays we have the possibility to exclude also the Interlocking function if the staff is sure that the requested operation is safely.

In order to exclude the interlocking from the control relays there is the following procedure:

1. Press the "CONTROL" $\rightarrow$ APPARATUSSES $\rightarrow$ L/R button (in order to take over the control jurisdiction from the workstation to the local relay) $\rightarrow$ then press the return button $\rightarrow$ currently we can see the "synkrochek bypass" and "interlock bypass" options and we so we can exclude the demanded inhibition.

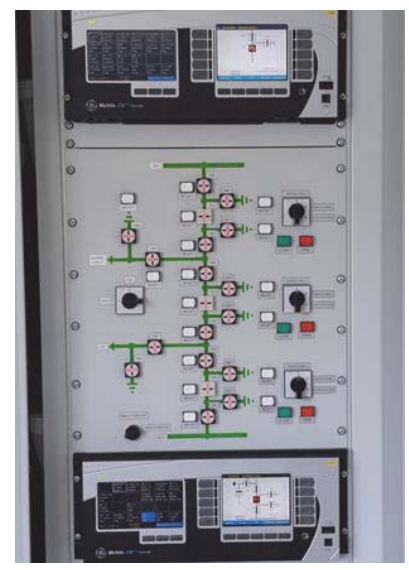

Figure 9: $220 \mathrm{kV}$ Control Panel of one Diameter

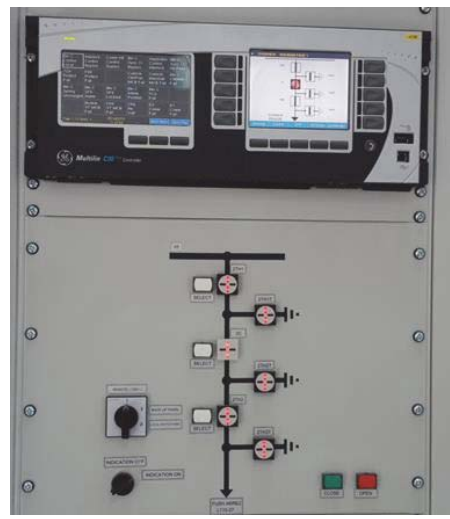

Figure 10: $110 \mathrm{kV}$ Control Panel of one Bay 
The command from the panel is taken by switching the switch at the panel from "Remote" at "Backup Panel" statment. Thereafter it is possible to select the respective elements or components in order to be controlled through the "Close" or "Open" button. It should be emphasized that at this control level we are dealing with electrical interlocks and at the same time we have exclude the software interlocks. So it means that the descending from one control level to another one increases the chance of human error. (Prozanet, 2015).

\section{Implementation of the logic in order to accomplish the visualization of the control authority.}

\subsection{Separation of the control priorities between OST and KESH.}

At the four control panels of the diameters at 220kV side where the units are synchronized ther is placed a logical switch wich changes the control jurisdiction of $\mathrm{C} 2$ with the respective disconnectors N3 and N4 from OST to KESH and vice versa. This action is visualized at the monitor schematic by switching from KESH showing at the monitor with red color to OST showing at the Human machine interface with green color.

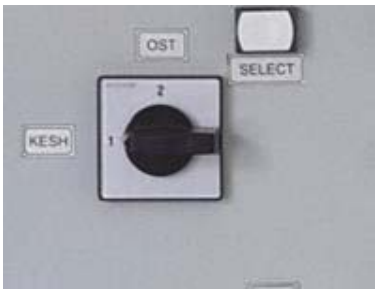

Figure 11: KESH/OST logical Switch

The Logical implementation in the Prozanet function PM Block is given in table 1.

Table 1: PM Block logic implementation

\begin{tabular}{|l|l|l|l|l|l|l|}
\hline SS FIERZA. Bay Remo & 10 andif & 0 & 1 & 0 & 1 NULL & $x$ \\
\hline SS FIERZA. OST & 10 andif & 1 & 1 & 0 & 0 NULL & $x$ \\
\hline SS FIERZA. KESH & 10 andif & 0 & 0 & 1 & 1 NULL & $x$ \\
\hline SS FIERZA. OST/KESH & 10 andif & 1 & 1 & 0 & 0 NULL & 0 \\
\hline
\end{tabular}

The input variables in the logical block are:

1. Bay in Remote

2. Logical switch in OST position.

3. Logical switch in KESH position.

The output variable of the function is OST/KESH, which will be 1 in case that the control priority of $\mathrm{C} 2$ is taken from OST and 0 if the control priority is taken from KESH.

The function that is in use at this case take into account all the cases that matters to us, while the other eventual combination are evaluated with $\mathrm{x}$ and with the output 0 . In table 1 it is shown a fraction of the logic block that is in use at the Fierza substation. The third column of the table means that this is the logical block number 10 which is implemented at PM Block, while the successive column defines the Bool's algebra operator that the PM Block module will execute at the successive columns. So it means that at column 5 for example, the position of the relays switch is at remote control state (1), and the position of the logic switch KESH/OST is at OST state (1) and therefore the KESH (0) statement is not active.

So at the workstation monitor of the substation will visualized OST with green color in case that the OST/KESH takes the value 1 and otherwise it will visualized KESH with red color if the in case that the value is 0 .

The workstation that is placed at the control room in the hydro power plant (KESH Property), the visualization colors of this logic are chosen the opposite, so value 0 of the variable OST respectively 1 for KESH variable visualizes KESH with green color in the opposite logic position OST is than with red color. To accomplish this an dynamic format extra for the KESH client is configured with behaves the opposite of the operator clients( Human machine interfaces) 


\section{Conclusions}

Fierza substation today manly is operated from OST personal. Every problem that may arise at the substation elements is shown directly in the event list and the alarm list. All $220 \mathrm{kV}$ and $110 \mathrm{kV}$ elements today can be controlled from the National Dispatching Center, since the successful implementation of the new Central Dispatching center and the full automation of the Fierza Substation with Prozanet. All these elements have increased the reliability for the operation of the Substation itself and also of the Albanian Power System. The separation of the authority jurisdiction between OST and $\mathrm{KESH}$, has increased the responsibility of the working staff of each company, regarding the successive control during the maintenance and operation process of the primary equipment. The Human machine interface visualization gives the opportunity to the operating staff to identify at first sight who is in charge of control in one certain moment. The Workstation in the KESH building also gives KESH the opportunity to monitor the status of the $110 \mathrm{kV}$ substation as well as the auxiliary supply status of the substation

\section{References}

Daniel Nack. (2005). Reliability of Substation Configurations. Iowa State University, , 7.

http://sq.wikipedia.org/wiki/Korporata_Elektroenergjitike_Shqiptare. (2015, 04 2). Wikipedia.org. Retrieved 05 20, 2015, from Wikipedia.org: http://sq.wikipedia.org/wiki/Korporata_Elektroenergjitike_Shqiptare

kirian111. (2015, 05 20). http://kiran111.hubpages.com/hub/Switching-Schemes-Busbar-Arrangements-Substation. Retrieved 0520 , 2015, from http://kiran111.hubpages.com/hub/Switching-Schemes-Busbar-Arrangements-Substation: http://kiran111.hubpages.com /hub/Switching-Schemes-Busbar-Arrangements-Substation

OST.al. (2015, Mai 20). http://ost.al/index.php/en/transmission-system/description. Retrieved Mai 20, 2015, from ost.al: http://ost.al/index.php/en/transmission-system/description

Prozanet. (2015, 05 20). Prozanet . Retrieved 05 20, 2015, from Koncar KET Prozanet: http://demo.multilink.hr/2012/koncarket/en/Home.aspx?PageName=Prozanet 